\title{
Cost-effectiveness of human papillomavirus vaccination in Germany
}

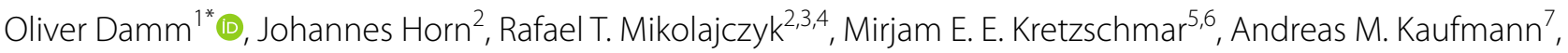
Yvonne Deleré ${ }^{8}$, Bernhard Ultsch ${ }^{9}$, Ole Wichmann ${ }^{9}$, Alexander Krämer ${ }^{10}$ and Wolfgang Greiner ${ }^{1}$

\begin{abstract}
Background: The aim of this study was to assess the cost-effectiveness of human papillomavirus (HPV) vaccination in addition to the current cervical cancer screening programme in Germany using a dynamic transmission model.

Methods: Based on a mathematical model simulating the transmission dynamics and the natural history of HPV infection and associated diseases (cervical intraepithelial neoplasia, cervical cancer, and genital warts), we estimated the epidemiological and economic consequences of HPV vaccination with both the quadrivalent and bivalent vaccines. In our base case analysis, we assessed the cost-effectiveness of vaccinating 12-year-old girls with a 3-dose schedule. In sensitivity analysis, we also evaluated the use of a 2-dose schedule and assessed the impact of vaccinating boys.

Results: From a health care payer perspective, incremental cost-effectiveness ratios (ICERs) of a 3-dose schedule were $€ 34,249$ per quality-adjusted life year (QALY) for the bivalent and $€ 14,711$ per QALY for the quadrivalent vaccine. Inclusion of indirect costs decreased ICERs by up to $40 \%$. When adopting a health care payer perspective, ICERs of a 2-dose approach decreased to $€ 19,450$ per QALY for the bivalent and to $€ 3645$ per QALY for the quadrivalent vaccine. From a societal perspective, a 2-dose approach using the quadrivalent vaccine was a cost-saving strategy while using the bivalent vaccine resulted in an ICER of $€ 13,248$ per QALY. Irrespective of the perspective adopted, additional vaccination of boys resulted in ICERs exceeding $€ 50,000$ per QALY, except for scenarios with low coverage (20\%) in girls.

Conclusions: Our model results suggest that routine HPV vaccination of 12-year-old girls with three doses is likely to be cost-effective in Germany. Due to the additional impact on genital warts, the quadrivalent vaccine appeared to be more cost-effective than the bivalent vaccine. A 2-dose schedule of the quadrivalent vaccine might even lead to cost savings when adopting a societal perspective. The cost-effectiveness of additional vaccination of boys was highly dependent on the coverage in girls.
\end{abstract}

Keywords: HPV, Vaccination, Economic evaluation, Cost-effectiveness, Dynamic transmission model, Germany

\section{Background}

Persistent infection with high-risk (oncogenic) types of human papillomavirus (HPV) is the main cause of cervical cancer and its precursors [1]. Infection with high-risk HPV types can also cause other types of anogenital cancer (i.e. vaginal, vulvar, anal, and penile cancer) and oropharyngeal cancer [2,3], whereas infection with low-risk

\footnotetext{
*Correspondence: oliver.damm@uni-bielefeld.de

${ }^{1}$ Department of Health Economics and Health Care Management,

School of Public Health, Bielefeld University, Universitätsstraße 25,

33615 Bielefeld, Germany

Full list of author information is available at the end of the article
}

(non-oncogenic) HPV types is primarily associated with genital warts [4].

Clinical studies have demonstrated high efficacy of prophylactic HPV vaccines in the prevention of HPV infections, premalignant anogenital lesions (cervical, vaginal, vulvar, and anal lesions), and genital warts [5-7]. In Germany, there are currently three HPV vaccines available to prevent HPV infection and related diseases: a bivalent vaccine $\left(\right.$ Cervarix $\left.^{\circledR}\right)$, a quadrivalent vaccine $\left(\right.$ Gardasi $\left.^{\circledR}\right)$, and a 9-valent vaccine (Gardasil ${ }^{\circledR}$ 9). All three vaccines protect against the high-risk genotypes 16 and 18, which cause approximately $70 \%$ of all cervical cancer cases 
[8]. The quadrivalent vaccine is additionally directed against the low-risk genotypes 6 and 11, which account for approximately $90 \%$ of genital warts [9]. The recently approved 9-valent version of Gardasil ${ }^{\circledR}$ protects against the four strains of the quadrivalent vaccine and five additional high-risk strains (31, 33, 45, 52, and 58). All available vaccines are licensed for use in females and males.

In Germany, routine HPV vaccination with two doses is currently recommended for females aged 9-14 years $[10,11]$. However, three doses are necessary when vaccinating adolescent girls aged 15-17 years (due to delayed initiation or series completion) or when the interval between the first and the second dose falls below 6 months. Before August 2014, three HPV vaccine doses were recommended for females aged 12-17 years. Both recommendations have primarily aimed at preventing cervical cancer. Since 1971, a cervical cancer screening programme is implemented in Germany, which is currently based on an annual Pap smear beginning at the age of 20 years.

No independently funded dynamic transmission model analysing the cost-effectiveness of HPV vaccination in the German health care setting, which can support the national decision-making process of the Standing Vaccination Committee (STIKO), has been published yet.

The purpose of this study was threefold: (a) to assess the cost-effectiveness of the bivalent and quadrivalent vaccines in addition to the existing cervical cancer screening programme in Germany using a dynamic transmission model, (b) to quantify the economic impact of switching from a 3-dose to a 2-dose schedule, and (c) to compare our results with findings of previously published studies on the cost-effectiveness of HPV vaccination in Germany.

\section{Methods}

\section{Overview}

We developed a mathematical model simulating the transmission dynamics and the natural history of HPV infection and associated diseases to evaluate the epidemiological and economic consequences of HPV vaccination in Germany. The age-structured model takes account of the occurrence of cervical intraepithelial neoplasia (CIN), cervical cancer, and genital warts. It was calibrated using German cancer statistics and other data. In the base case analysis, which was conducted from both a health care payer and a societal perspective, $\mathrm{HPV}$ vaccination of 12 year old girls in conjunction with the existing cytological screening programme was compared to screening alone. The time horizon was set to 100 years after the introduction of HPV vaccination. Epidemiological and economic parameter estimates were obtained from published literature and supplemented by expert interviews. The model was programmed using the software R. All cost calculations were performed using Microsoft Excel. Details on the methods and data sources used to construct the model are described in the following sections. A more detailed description of the underlying epidemiological model and the corresponding model parameters regarding the transmission of HPV, the natural history of cervical HPV infection, and the simulated screening programme has been published previously [12].

\section{Model structure}

The basic model structure combines an age-structured deterministic compartmental model, which simulates the sexual transmission of HPV, with a model that represents the natural history of cervical cancer.

The transmission dynamics are described by a SIRSmodel where the population is divided into susceptible individuals (S), infectious individuals (I), and recovered (and therefore immune) individuals (R). Our model considers six groups of viral strains: HPV 16, HPV 18, phylogenetically related high-risk types with potential for cross-protection (HPV 31/33/35/39/45/51/52/56/58/59), other high-risk types without potential for cross-protection, HPV 6/11, and other low-risk types. We neglected any synergistic and antagonistic interactions between different HPV types as multi-strain interactions are subject to controversy.

To estimate the long-term consequences of HPV infection, the transmission model was complemented by a module covering the cervical carcinogenesis. This part of the model includes type-specific health states for having CIN of three grades (CIN 1, CIN 2, or CIN 3), having carcinoma in situ (CIS), and having invasive cervical cancer of different stages according to the International Federation of Gynecology and Obstetrics (FIGO) classification system. CIS and invasive cancer states were further subdivided into undetected and detected disease states. For women who had undergone hysterectomy, only transitions between the susceptible, infected, and immune (recovered) states were permitted. Therefore, with the exception of sexual mixing and background mortality, those women were modelled identically to males who were only allowed to move between the susceptible, infected, and immune states. The occurrence of genital warts in both genders was modelled as an event that was linked with incident infections with low-risk types, but only a proportion of those newly infected individuals were assumed to develop clinical symptoms of genital warts and to seek medical treatment. A simplified flow diagram of the model structure representing the natural history of HPV infection and cervical cancer in women is outlined in Fig. 1. 


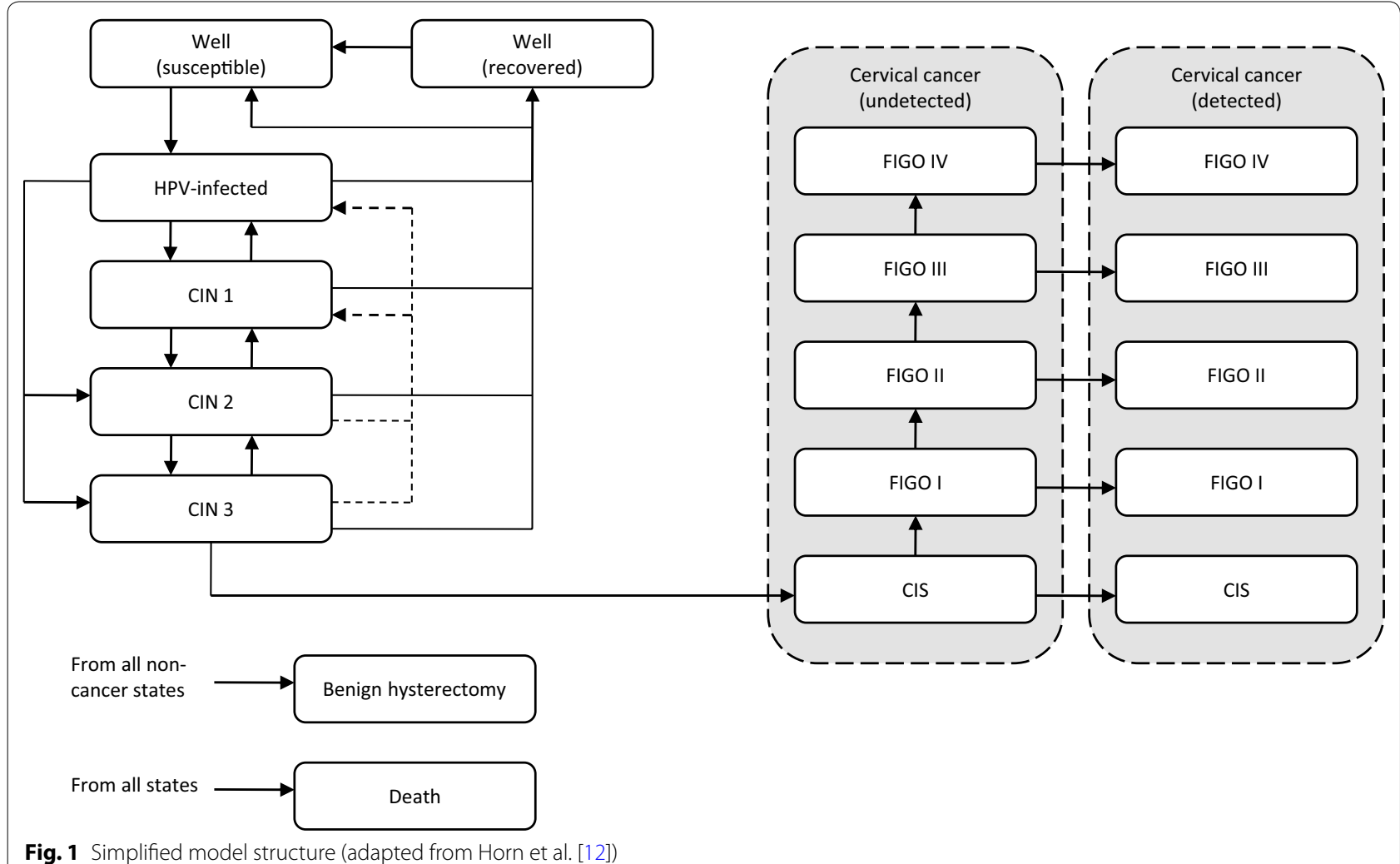

\section{Data sources and model inputs}

\section{Demographic, behavioural, and transmission parameters}

The model population is based on a constant number of one million births per year and the 2008 mortality rates in Germany derived from the Federal Statistical Office. Our model focusses on heterosexual transmission of HPV infection only. We assumed the sexual debut to be at the age of 12 years and divided the sexually active population into ten age groups $(12-13,14-15,16-17,18-24$, $25-34,35-44,45-54,55-64,65-74$, and $75-100$ years) and three sexual activity-based risk groups (low, moderate, and high activity). The proportions of individuals belonging to the different activity classes were 80,15 , and $5 \%$ for the low, moderate, and high activity groups, respectively [13]. The mixing patterns between individuals of the different age and risk groups were determined by two mixing parameters. These parameters for the assortativeness of mixing by age and by risk group were set to 0.4 and 0.3 , respectively [14]. An assortativeness by age of 0.4 means that $40 \%$ of new sexual partners are preferentially chosen from the same age group while the remaining sexual partners are chosen proportionally from all age groups depending on their size. An assortativeness by risk group of 0.3 means that $30 \%$ of partners are preferentially chosen within the same sexual activity group while the remaining sexual partners are chosen proportionally from all sexual activity groups depending on their size. As robust German data on patterns of sexual behaviour were lacking, we used data from the transmission model by Zechmeister et al. [15], which had been originally derived from British and Norwegian surveys of sexual behaviour.

\section{Natural history}

The initial values of the epidemiological model parameters regarding the natural history of cervical cancer were obtained from the published literature, particularly from previous modelling studies [14, 16-20]. Whereas some parameter values were directly incorporated in our model, other values were derived through calibration. Details on the parameter values used in our model are provided in an article by Horn et al. [12].

Not every HPV infection is followed by the development of a type-specific resistance. Hence, we only allowed a fraction of the infected population to be immune after infection for a certain period of time [21]. The proportion of individuals experiencing a seroconversion was estimated to be $60 \%$ [22]. The fraction of seroconverted individuals developing a naturally acquired immunity was estimated to be $30 \%$ [23]. Waning of naturally acquired immunity was assumed to be $10 \%$ per year resulting in an average type-specific immunity of 10 years. 
In our model, the CIS state was subdivided into two compartments as proposed by Insinga et al. [24] to avoid short transition times from CIS to invasive cancer resulting from the exponential distribution.

\section{Screening programme}

The screening module of our model was constructed to reflect the current screening practice in Germany. We applied age-specific screening coverage rates that were obtained from German data [25] and assumed the proportion of women who never participate in screening to be $7 \%$ as done in other modelling studies $[18,19]$. To simulate the future effects of the stepwise increase in screening coverage in Germany during the 1990s and to prevent an overestimation of the vaccine-induced reduction in cervical cancer-related burden of disease, we incorporated historical changes in screening uptake in our model. For this purpose, we combined the current age-specific screening coverage rates with the observed changes in participation in early cancer detection programmes over time [26]. Diagnostic follow-up (including management of abnormal cervical cytology and histology) was modelled by the use of integrated decision trees. The construction of these decision trees was based on clinical guidelines, empirical studies, health economic models, and an interview with members of the German working group on cervical pathology and colposcopy that was conducted explicitly for this purpose.

\section{Vaccination}

In the base case scenario, we analysed the cost-effectiveness of vaccinating 12-year-old girls with three doses. Vaccination coverage was assumed to be $50 \%$ based on several studies assessing HPV vaccine uptake in Germany [27-32]. In these studies, reported uptake, defined as receipt of at least one HPV vaccine dose, ranged from 30 to $60 \%$. When considering only those females who received the full course of three doses, uptake ranged from 27 to $48 \%$. We assumed completion of the 3-dose series for all girls who initiated vaccination. All analyses were carried out for both the bivalent and quadrivalent vaccines. Vaccine efficacy against HPV 16/18 infection was estimated to be $98 \%$ for both vaccines, and vaccine efficacy in preventing HPV 6/11 infection was estimated to be $100 \%$ for the quadrivalent vaccine. Cross-protection against non-vaccine oncogenic HPV-types was not considered in the base case scenario but was explored in sensitivity analysis taking the different cross-protection profiles of the vaccines into account. Currently, the maximum duration of vaccine protection is unknown. Clinical efficacy against type-specific infection and associated diseases has been demonstrated up to 9.4 years post-vaccination [33], but long-term persistence of antibody responses has been predicted by statistical modelling of individual antibody data $[34,35]$. Taking both the evidence based on limited follow-up of adolescent girls and women in clinical trials and the predictions of statistical models into account, we decided to assume a 10 years lasting initial period of sustained vaccine protection followed by a period of waning immunity using a waning rate of $10 \%$ per year. This approach resulted in an average duration of vaccine-induced immunity of 20 years. We separately examined the impact of lifelong protection as well as the influence of administering a booster dose in sensitivity analysis. While in the base case scenario vaccination was restricted to girls, immunisation of boys was assessed in sensitivity analysis. A 2-dose schedule was also examined in sensitivity analysis. All vaccinationrelated input data are presented in Table 1.

\section{Resource utilisation and direct health care costs}

Our model takes into account resource use associated with vaccination, screening, management of abnormal cytological screening results, management and treatment of biopsy-confirmed CIN, and treatment of cervical cancer and genital warts. Direct health care costs were calculated considering all relevant cost components that are reimbursed by the statutory health insurance. These components include medication, physician consultations, outpatient diagnostic procedures, laboratory testing, therapeutic appliances and outpatient health care services provided by non-physicians (i.e. medical compression tights and manual lymphatic drainage as part of lymphoedema treatment), and hospitalisations.

Treatment patterns and related resource consumption were mainly derived from clinical guidelines and published studies on the current management of cervical cancer and its precursors [36-39]. Literature-based evidence was supplemented by expert opinion to account for missing data for Germany and variation in clinical practice. For instance, the experts were asked to estimate the stage-specific frequency of utilisation for different outpatient and inpatient treatment procedures of cervical cancer. A total of six expert interviews with gynaecologists were conducted by telephone or in written form. Table 2 gives an overview of the assumed treatment patterns and resource utilisation in the treatment and posttreatment follow-up of cervical cancer.

Most unit costs were based on official German price lists, fee scales, or catalogues. Vaccine prices and drug costs were obtained from the pharmaceutical database LAUER-TAXE ${ }^{\circledR}$ [40]. The cost per dose of both vaccines was estimated at $€ 150.41$. The mean vaccine administration fee was calculated to be $€ 7.50$ per dose, based on a review of the immunisation fee scales of all regional 
Table 1 Vaccination-related input variables

\begin{tabular}{|c|c|c|c|}
\hline Parameter & Value & & Source \\
\hline \multirow[t]{4}{*}{ Vaccine efficacy } & HPV $16 / 18$ in females & $98 \%$ & {$[81,82]$} \\
\hline & HPV 6/11 in females (quadrivalent vaccine only) & $100 \%$ & {$[83]$} \\
\hline & HPV $16 / 18$ in males & $90.4 \%$ & {$[84]$} \\
\hline & HPV 6/11 in males (quadrivalent vaccine only) & $90.4 \%$ & {$[84]$} \\
\hline $\begin{array}{l}\text { Cross-protection provided by the quadrivalent vaccine } \\
\text { (considered in sensitivity analysis only) }\end{array}$ & HPV 31/33/35/39/45/51/52/56/58/59 & $32.5 \%$ & {$[85,86]$} \\
\hline $\begin{array}{l}\text { Cross-protection provided by the bivalent vaccine } \\
\text { (considered in sensitivity analysis only) }\end{array}$ & HPV 31/33/35/39/45/51/52/56/58/59 & $68.4 \%$ & {$[86]$} \\
\hline Duration of full protection & 10 years & & Assumption \\
\hline Waning (after the duration of full protection) & 0.1 per year & & Assumption \\
\hline Vaccination coverage & $50 \%$ & & Assumption \\
\hline Age at vaccination & 12 years & & Assumption \\
\hline Booster vaccination & No booster vaccination in the base case analysis & & Assumption \\
\hline
\end{tabular}

HPV human papillomavirus

Associations of Statutory Insurance Physicians in Germany. Charges for outpatient visits as well as outpatient diagnostic and treatment procedures were based on the physician fee scale (Einheitlicher Bewertungsmaßstab, EBM) of the statutory health insurance. Hospitalisation costs were retrieved from the German diagnosis-related group (DRG) catalogue using a base rate of $€ 2935.78$ and the cost weights of various DRGs (N01A, N01E, N03B, N09Z, N15Z, and N60A). Costs of inpatient palliative care and treatment were calculated assuming a length of stay of 30 days and combining the DRG N60B with a supplementary fee for palliative care (ZE60.01). All direct costs were adjusted for patient co-payments. Cost estimates for treating CIN 3 and CIS were taken from a German resource use study providing intervention costs associated with a PAP IV diagnosis of the Munich Cytological Classification, which corresponds to severe dysplasia and CIS [41]. Costs for treating genital warts were based on own calculations using data from a German cost-of-illness study [42]. All costs are reported in 2010 euros. Where 2010 prices were not available, prices were inflated to 2010 values using the German consumer price index (CPI). The base case values of the aggregated direct health care costs are summarised in Table 3.

\section{Indirect costs}

Indirect costs in terms of production losses were considered when adopting a societal perspective. Data on absence from work due to HPV-associated illness were obtained from the statistics of a German sickness fund [43] using year 2008 information. Indirect costs were calculated by the friction cost approach assuming the friction period equal to the average duration of a vacant job position. According to a report of the Federal
Employment Agency [44], this period was assumed to be 63 days. Cost per work day lost was estimated at $€ 85.13$ using 2010 data on monetary compensation and number of employees in Germany from the Federal Statistical Office [45]. Indirect costs due to CIN and cervical cancer were weighted by age-specific employment rates of women to avoid an overestimation of the production losses. All indirect cost inputs are summarised in Table 4.

\section{Health state utilities}

In the absence of utility values that are specific to Germany, the data for calculating quality-adjusted life years (QALYs) were taken from the international literature and previous health economic models. These studies applied different methods for eliciting QALY weights including the use of the EQ-5D questionnaire [46], the time tradeoff technique [47], and an expert-based application of the Health Utility Index (HUI) Mark II [48]. The selection of utility values was guided by the model structure. The utility values used in our model are presented in Table 5 . We assumed the baseline utility value of normal health to be 1.0. Estimates for the duration of reductions in quality of life were mainly based on expert opinion. QALY losses associated with Pap smear-based screening and diagnostic follow-up of cytological and histological results were not considered in our modelling approach.

\section{Discounting}

In the base case analysis, future costs and health effects were discounted at an annual rate of $3 \%$ as recommended by guidelines of the Institute for Quality and Efficiency in Health Care [49] and the STIKO [10]. Other German recommendations on health economic evaluation, also referred to as Hanover Consensus, favour a discount rate 
Table 2 Treatment patterns and resource utilisation in the treatment and post-treatment follow-up of cervical cancer (percentages are average values based on experts' responses)

\begin{tabular}{|c|c|c|}
\hline $\begin{array}{l}\text { Cervical cancer stage (FIGO } \\
\text { classification) or treatment phase }\end{array}$ & Treatment patterns and resource utilisation & \\
\hline \multirow[t]{4}{*}{ FIGOIA1 } & Conisation & $60 \%$ \\
\hline & Conisation with pelvic lymph node dissection & $10 \%$ \\
\hline & Simple hysterectomy & $20 \%$ \\
\hline & Simple hysterectomy with pelvic lymph node dissection & $10 \%$ \\
\hline \multirow[t]{4}{*}{$\mathrm{FIGO} \mid \mathrm{A} 2$} & Conisation with pelvic lymph node dissection & $20 \%$ \\
\hline & Radical trachelectomy with pelvic lymph node dissection & $10 \%$ \\
\hline & Simple hysterectomy & $10 \%$ \\
\hline & Simple hysterectomy with pelvic lymph node dissection & $60 \%$ \\
\hline \multirow[t]{4}{*}{$\mathrm{FIGO} \mid \mathrm{B} 1$} & Radical hysterectomy with pelvic lymph node dissection & $64 \%$ \\
\hline & Radical hysterectomy with pelvic lymph node dissection and adjuvant chemoradiotherapy & $16 \%$ \\
\hline & Radical trachelectomy with pelvic lymph node dissection & $5 \%$ \\
\hline & Chemoradiotherapy & $15 \%$ \\
\hline \multirow[t]{3}{*}{ FIGO IB2 } & Radical hysterectomy with pelvic and paraaortic lymph node dissection & $49 \%$ \\
\hline & $\begin{array}{l}\text { Radical hysterectomy with pelvic and paraaortic lymph node dissection and adjuvant chemoradio- } \\
\text { therapy }\end{array}$ & $21 \%$ \\
\hline & Chemoradiotherapy & $30 \%$ \\
\hline \multirow[t]{3}{*}{ FIGO IIA } & Radical hysterectomy with pelvic and paraaortic lymph node dissection & $35 \%$ \\
\hline & $\begin{array}{l}\text { Radical hysterectomy with pelvic and paraaortic lymph node dissection and adjuvant chemoradio- } \\
\text { therapy }\end{array}$ & $15 \%$ \\
\hline & Chemoradiotherapy & $50 \%$ \\
\hline \multirow[t]{3}{*}{ FIGO IIB } & Radical hysterectomy with pelvic and paraaortic lymph node dissection & $12 \%$ \\
\hline & $\begin{array}{l}\text { Radical hysterectomy with pelvic and paraaortic lymph node dissection and adjuvant chemoradio- } \\
\text { therapy }\end{array}$ & $18 \%$ \\
\hline & Chemoradiotherapy & $70 \%$ \\
\hline \multirow[t]{3}{*}{ FIGO IIIA } & Radical hysterectomy with pelvic and paraaortic lymph node dissection & $2 \%$ \\
\hline & $\begin{array}{l}\text { Radical hysterectomy with pelvic and paraaortic lymph node dissection and adjuvant chemoradio- } \\
\text { therapy }\end{array}$ & $8 \%$ \\
\hline & Chemoradiotherapy & $90 \%$ \\
\hline \multirow[t]{3}{*}{ FIGO IIIB } & Radical hysterectomy with pelvic and paraaortic lymph node dissection & $2 \%$ \\
\hline & $\begin{array}{l}\text { Radical hysterectomy with pelvic and paraaortic lymph node dissection and adjuvant chemoradio- } \\
\text { therapy }\end{array}$ & $8 \%$ \\
\hline & Chemoradiotherapy & $90 \%$ \\
\hline \multirow[t]{5}{*}{ FIGO IVA } & Radical hysterectomy with pelvic and paraaortic lymph node dissection & $2 \%$ \\
\hline & $\begin{array}{l}\text { Radical hysterectomy with pelvic and paraaortic lymph node dissection and adjuvant chemoradio- } \\
\text { therapy }\end{array}$ & $8 \%$ \\
\hline & Chemoradiotherapy & $80 \%$ \\
\hline & Exenteration & $2 \%$ \\
\hline & Exenteration and adjuvant chemoradiotherapy & $8 \%$ \\
\hline \multirow[t]{2}{*}{ FIGO IVB } & Chemoradiotherapy & $40 \%$ \\
\hline & Palliative chemotherapy & $60 \%$ \\
\hline \multirow[t]{3}{*}{ Post-treatment follow-up } & Outpatient visits, Pap-smears, and pelvic and abdominal ultrasonography & $100 \%$ \\
\hline & Hormone replacement therapy (women $<50$ years) & $50 \%$ \\
\hline & Manual lymphatic drainage and medical compression tights & $10-30 \%$ \\
\hline
\end{tabular}

FIGO International Federation of Gynecology and Obstetrics

of 5\% [50], which was considered in sensitivity analysis. In addition, we assessed the impact of differential discounting (3\% for costs and $1.5 \%$ for health effects) [51].
Analytic strategy and sensitivity analysis

To determine the cost-effectiveness of the introduction of HPV vaccination in Germany, we calculated incremental 
Table 3 Direct health care costs

\begin{tabular}{|c|c|c|}
\hline Parameter & Direct costs (€, 2010 price level) & \\
\hline \multicolumn{3}{|l|}{ Vaccination costs } \\
\hline Vaccine (initial series of 3 doses) & 451.23 & \\
\hline Administration (initial series of 3 doses) & 22.50 & \\
\hline Booster shot (per dose) & 150.41 & \\
\hline Administration of booster shot (per dose) & 7.50 & \\
\hline \multicolumn{3}{|c|}{ Costs of screening, management of abnormal cytological screening results, and observational follow-up of CIN 1 and CIN 2} \\
\hline Cytological screening (Pap smear) & 25.23 & \\
\hline \multirow[t]{2}{*}{ Follow-up smear (including quarterly Gynaecologist's fee and optional colposcopy) } & $\leq 59$ years & 20.15 \\
\hline & $60+$ years & 20.33 \\
\hline \multirow[t]{2}{*}{ HPV test (including quarterly Gynaecologist's fee) } & $\leq 59$ years & 44.77 \\
\hline & $60+$ years & 44.94 \\
\hline \multirow[t]{2}{*}{ HPV test and follow-up smear (including quarterly Gynaecologist's fee) } & $\leq 59$ years & 50.55 \\
\hline & $60+$ years & 50.73 \\
\hline \multirow[t]{2}{*}{ Colposcopy (including quarterly Gynaecologist's fee) } & $\leq 59$ years & 14.37 \\
\hline & $60+$ years & 14.54 \\
\hline Biopsy and histology & 129.47 & \\
\hline \multicolumn{3}{|l|}{ Costs of CIN/CIS treatment and post-treatment follow-up } \\
\hline \multirow[t]{3}{*}{ Conisation of the cervix (CIN 1 and CIN 2) } & $\leq 39$ years & 525.05 \\
\hline & $40-59$ years & 531.22 \\
\hline & $60+$ years & 534.17 \\
\hline Treatment of CIN 3 and CIS & 1621.53 & \\
\hline \multirow[t]{2}{*}{ Post-treatment follow-up of CIN/CIS (year 1 and 2 after treatment) } & $\leq 59$ years & 70.71 \\
\hline & $60+$ years & 71.06 \\
\hline \multicolumn{3}{|l|}{ Costs of cervical cancer treatment and post-treatment follow-up } \\
\hline \multirow[t]{2}{*}{ Diagnostics of symptom-detected cervical cancer } & $\leq 59$ years & 323.03 \\
\hline & $60+$ years & 324.08 \\
\hline \multirow[t]{2}{*}{ Diagnostics of screen-detected cervical cancer } & $\leq 59$ years & 179.18 \\
\hline & $60+$ years & 180.06 \\
\hline \multirow[t]{2}{*}{ Treatment of cervical cancer (FIGO I) } & $\leq 59$ years & 7586.98 \\
\hline & $60+$ years & 7591.22 \\
\hline \multirow[t]{2}{*}{ Treatment of cervical cancer (FIGO II) } & $\leq 59$ years & $11,455.22$ \\
\hline & $60+$ years & $11,456.94$ \\
\hline \multirow[t]{2}{*}{ Treatment of cervical cancer (FIGO III) } & $\leq 59$ years & $12,380.21$ \\
\hline & $60+$ years & $12,380.70$ \\
\hline \multirow[t]{2}{*}{ Treatment of cervical cancer (FIGO IV) } & $\leq 59$ years & $10,615.72$ \\
\hline & $60+$ years & $10,616.21$ \\
\hline \multirow[t]{3}{*}{ Post-treatment follow-up of cervical cancer (year 1 after treatment) } & $\leq 49$ years & 841.53 \\
\hline & $50-59$ years & 835.65 \\
\hline & $60+$ years & 836.35 \\
\hline \multirow[t]{3}{*}{ Post-treatment follow-up of cervical cancer (year 2 after treatment) } & $\leq 49$ years & 428.13 \\
\hline & $50-59$ years & 422.25 \\
\hline & $60+$ years & 422.95 \\
\hline \multirow[t]{3}{*}{ Post-treatment follow-up of cervical cancer (year 3 after treatment) } & $\leq 49$ years & 352.42 \\
\hline & $50-59$ years & 346.54 \\
\hline & $60+$ years & 347.24 \\
\hline \multirow[t]{3}{*}{ Post-treatment follow-up of cervical cancer (year 4 and 5 after treatment) } & $\leq 49$ years & 282.50 \\
\hline & $50-59$ years & 276.62 \\
\hline & $60+$ years & 276.97 \\
\hline
\end{tabular}


Table 3 continued

\begin{tabular}{ll}
\hline Parameter & Direct costs (€, 2010 price level) \\
\hline Post-treatment follow-up of cervical cancer (from year 6 after treatment onwards) & $\leq 49$ years \\
& $50-59$ years \\
& $60+$ years \\
Inpatient palliative care and treatment & 7518.09 \\
Costs of genital warts treatment & \\
Treatment of genital warts in females & 572.14 \\
Treatment of genital warts in males & 396.69 \\
\hline
\end{tabular}

CIN cervical intraepithelial neoplasia, CIS carcinoma in situ, FIGO International Federation of Gynecology and Obstetrics

cost-effectiveness ratios (ICERs) using life years (LYs) gained and QALYs gained as outcome measures. The base case analysis was carried out from the German health care payer perspective, which is the perspective of the statutory health insurance funds (taking account of reimbursed direct costs only), and from the societal perspective (considering reimbursed direct costs as well as indirect costs). Patient co-payments were not included in both perspectives since not all relevant sources provided sufficient details on that aspect.

We evaluated the long-term health and economic effects of vaccinating 12-year-old girls against HPV alongside the current cytology-based cervical cancer screening programme compared to an exclusive continuation of the cytological screening programme. Deterministic sensitivity analyses were performed to test the robustness of the results to changes in model input data and assumptions. The impact of varying single model parameters was examined by one-way sensitivity analyses. Parameters varied were characteristics of the vaccination programme, costs, utilities, and the discount rate. Furthermore, we assessed the implication of incorporating vaccine-specific cross-protection and evaluated the additional impact of vaccinating boys. Since a 2-dose schedule showed equivalent antibody response and similar efficacy to the standard 3-dose regimen [52-54], we also analysed the cost-effectiveness of administering only two doses at the age of 12 years assuming the same level of protection. Multivariate sensitivity analyses were carried out in terms of best-case (6/11/16/18 efficacy: $100 \%$; vaccine-specific cross-protection: 32.5 or $68.4 \%$; lifelong protection; $20 \%$ increase in screening and treatment cost; $20 \%$ increase in quality of life detriments; societal perspective) and worst-case (6/11/16/18 efficacy: 80\%; no cross-protection; average duration of protection: 15 years; $20 \%$ decrease in screening and treatment cost; $20 \%$ decrease in quality of life detriments; health care payer perspective) analyses.

\section{Model calibration and validation}

Model calibration is the process of adjusting input parameter values until the simulation output matches empirical data. Our model was calibrated to reflect observations on age-specific prevalence of HPV infection [55-59], age-specific prevalence of CIN [60], agespecific incidence and mortality of cervical cancer [61], as well as HPV type-distribution in different cervical disease states [57, 62-65]. When data for Germany were not available, we used data from other countries. The modification of parameter values and the subsequent comparison of the simulation results with the observed data were performed manually. Furthermore, we used age-specific adjustment factors for four groups of parameters (progression probabilities of cancer, regression probabilities, detection of cancer by symptoms, and mortality of cervical cancer) to achieve a better fit to the observed data. More details regarding both the model calibration process and the results of the model validation have been previously published [12].

\section{Systematic literature review}

We performed a systematic literature review to compare our results with findings of previously published studies on the cost-effectiveness of HPV vaccination in Germany. A PubMed-based literature search was conducted using the following search terms: "HPV" OR "human papillomavirus") AND ("vaccine" OR "vaccination" OR "immunisation" OR "immunization") AND ("cost-effectiveness" OR "economic") AND "Germany". This search was complemented by scanning reference lists of previously identified full-text articles. A study was included if it met the following criteria: (i) it was an economic evaluation of HPV vaccination in Germany, (ii) it was conducted from a health care payer or a societal perspective, (iii) it was written in English or German, and (iv) it was published as a full-text article. 
Table 4 Indirect costs

\begin{tabular}{|c|c|c|c|}
\hline \multirow{2}{*}{$\begin{array}{l}\text { Parameter } \\
\text { Treatment of CIN } 1 \text { and CIN } 2\end{array}$} & \multirow{2}{*}{$\begin{array}{l}\text { Average absence from work (days) }^{\mathbf{a}} \\
15.9\end{array}$} & \multicolumn{2}{|c|}{ Indirect costs $(€, 2010 \text { price level })^{b}$} \\
\hline & & $15-19$ years & 336.50 \\
\hline & & 20-24 years & 835.26 \\
\hline & & $25-29$ years & 965.33 \\
\hline & & 30-34 years & 977.31 \\
\hline & & $35-39$ years & 1009.89 \\
\hline & & 40-44 years & 1063.18 \\
\hline & & $45-49$ years & 1060.82 \\
\hline & & $50-54$ years & 1010.30 \\
\hline & & $55-59$ years & 853.97 \\
\hline & & 60-64 years & 410.89 \\
\hline \multirow[t]{10}{*}{ Treatment of CIN 3 and CIS } & 21.3 & $15-19$ years & 450.79 \\
\hline & & 20-24 years & 1118.93 \\
\hline & & $25-29$ years & 1293.18 \\
\hline & & 30-34 years & 1309.23 \\
\hline & & $35-39$ years & 1352.87 \\
\hline & & 40-44 years & 1424.25 \\
\hline & & $45-49$ years & 1421.10 \\
\hline & & $50-54$ years & 1353.42 \\
\hline & & $55-59$ years & 1144.00 \\
\hline & & $60-64$ years & 550.44 \\
\hline \multirow[t]{10}{*}{ Treatment of cervical cancer (all FIGO stages) } & 44.4 & $15-19$ years & 939.67 \\
\hline & & 20-24 years & 2332.42 \\
\hline & & $25-29$ years & 2695.65 \\
\hline & & 30-34 years & 2729.11 \\
\hline & & $35-39$ years & 2820.06 \\
\hline & & 40-44 years & 2968.87 \\
\hline & & $45-49$ years & 2962.30 \\
\hline & & $50-54$ years & 2821.22 \\
\hline & & $55-59$ years & 2384.68 \\
\hline & & $60-64$ years & 1147.39 \\
\hline \multirow[t]{10}{*}{ Death due to cervical cancer (all FIGO stages) } & 63 (friction period) & $15-19$ years & 1333.31 \\
\hline & & 20-24 years & 3309.52 \\
\hline & & $25-29$ years & 3824.91 \\
\hline & & 30-34 years & 3872.38 \\
\hline & & $35-39$ years & 4001.44 \\
\hline & & 40-44 years & 4212.58 \\
\hline & & $45-49$ years & 4203.26 \\
\hline & & $50-54$ years & 4003.08 \\
\hline & & $55-59$ years & 3383.67 \\
\hline & & $60-64$ years & 1628.06 \\
\hline Treatment of genital warts in females & 7.7 & $15-64$ years & $30.81^{c}$ \\
\hline Treatment of genital warts in males & 8.7 & $15-64$ years & $28.14^{c}$ \\
\hline
\end{tabular}

CIN cervical intraepithelial neoplasia, CIS carcinoma in situ, FIGO International Federation of Gynecology and Obstetrics

a Average duration of absence from work in patients who missed work because of illness

${ }^{\mathrm{b}}$ Weighted by age-specific employment rates of women

c Not weighted by age-specific employment rates as the fraction of genital warts patients who missed work was estimated directly on the basis of a German study [42] 
Table 5 Utility values

\begin{tabular}{llll}
\hline Health state & Utility value & Duration & Source \\
\hline Treatment of CIN 1 & 0.91 & 2 months & {$[47]$} \\
Treatment of CIN 2 & 0.87 & 2 months & {$[47]$} \\
Treatment of CIN 3 & 0.87 & 2 months & {$[47]$} \\
Treatment of CIS & 0.80 & 2 months & {$[48]$} \\
Follow-up of CIS & 0.97 & 1.8 years $(22$ months) & {$[48]$} \\
Treatment of FIGO I & 0.65 & 6 months & {$[87]$} \\
Follow-up of FIGO I & 0.97 & Up to 4.5 years $(54$ months) & {$[48,87]$} \\
Treatment of FIGO II & 0.56 & 6 months & {$[87]$} \\
Follow-up of FIGO II & 0.90 & Up to 4.5 years $(54$ months) & {$[48,87]$} \\
Treatment of FIGO III & 0.56 & 6 months & {$[87]$} \\
Follow-up of FIGO III & 0.90 & Up to 4.5 years $(54$ months) & {$[48,87]$} \\
Treatment of FIGO IV & 0.48 & 6 months & {$[88]$} \\
Follow-up of FIGO IV & 0.62 & Up to 4.5 years $(54$ months) & {$[48,87]$} \\
Palliative care & 0.29 & 1 month & {$[89]$} \\
Treatment of genital warts & 0.93 & 2 months & {$[46,48]($ mean value of both sources) } \\
\hline
\end{tabular}

CIN cervical intraepithelial neoplasia, CIS carcinoma in situ, FIGO International Federation of Gynecology and Obstetrics

\section{Results}

\section{Public health impact and costs}

The continuation of the current cytology-based screening programme without additional HPV vaccination led to approximately 271,000 cervical cancer cases and about 78,000 cervical cancer deaths when considering a 100-year time horizon. In the same period, low-risk HPV infections caused about 10 million cases of genital warts. In our model, even without HPV vaccination, cervical cancer incidence decreased during the first years of the simulated time horizon, which was related to increased screening coverage in the past. Discounted direct costs were $€ 15.4$ billion for the scenario without vaccination. More than $60 \%$ of these costs were incurred by screening and related follow-up procedures.

With implemented HPV vaccination, our model projected about 171,000 cervical cancer cases and about 54,000 cervical cancer deaths. This means that supplementing the current screening practice with vaccination of 12-year-old girls with an assumed coverage of $50 \%$ prevented approximately 100,000 cervical cancer cases and 24,000 deaths over a time horizon of 100 years. These figures correspond to a $37 \%$ reduction in cervical cancer and a $30 \%$ reduction in cervical cancer mortality. Vaccination with the quadrivalent vaccine was additionally associated with an overall reduction in genital warts of $88 \%$. About $40 \%$ of all prevented cases of genital warts were prevented in males due to herd effects. Expected vaccination costs were $€ 3.5$ billion. Overall direct costs (compared to screening only) increased by $€ 2.8$ and $€ 1.6$ billion for the bivalent and the quadrivalent vaccine, respectively. Table 6 shows the discounted costs considering a 100-year time horizon.

\section{Cost-effectiveness}

Under base case assumptions, the discounted ICERs of a 3-dose schedule were $€ 53,807$ per LY and $€ 34,249$ per QALY for the bivalent vaccine and $€ 30,910$ per LY and $€ 14,711$ per QALY for the quadrivalent vaccine when adopting a health care payer perspective. Inclusion of indirect costs decreased the ICERs to $€ 28,047$ and $€ 8984$ per QALY for the bivalent and the quadrivalent vaccine, respectively. Cost-effectiveness results of the base case analysis are summarised in Table 7.

\section{Sensitivity analysis}

Model results were highly sensitive to assumptions about the discount rate and the vaccination age. Vaccinating 16-year-old girls was more cost-effective than vaccinating 12-year-old girls as long as no lifelong protection was assumed. Changes in duration of protection (minimum duration: 10 years of stable protection combined with instant waning of protection afterwards; maximum duration: lifelong protection) had a minor (quadrivalent vaccine) to moderate (bivalent vaccine) impact on the economic results. ICERs increased with increasing coverage due to the combination of diminishing marginal benefit of vaccine-induced protection in the population and linearly increasing vaccination cost. In scenarios with low coverage $(\leq 20 \%)$, the use of the quadrivalent vaccine led to cost savings from a societal perspective. However, a low coverage was also associated with fewer prevented 
Table 6 Discounted costs over a 100-year time horizon

\begin{tabular}{|c|c|c|c|}
\hline Discounted costs ( $€$ in thousands) & No vaccination & Bivalent vaccination & Quadrivalent vaccination \\
\hline \multicolumn{4}{|l|}{ Direct costs } \\
\hline Vaccine (3 doses) & 0 & $3,461,711$ & $3,461,711$ \\
\hline Vaccine administration (3 doses) & 0 & 172,614 & 172,614 \\
\hline Screening & $8,825,905$ & $8,829,506$ & $8,829,506$ \\
\hline $\begin{array}{l}\text { Diagnostic follow-up of abnormal cytological screening } \\
\text { results and observational management of CIN } 1 \text { and CIN } 2\end{array}$ & $1,481,795$ & $1,370,223$ & $1,349,669$ \\
\hline Treatment of CIN & $1,739,325$ & $1,387,470$ & $1,349,167$ \\
\hline Treatment of CIS & 498,381 & 347,349 & 347,349 \\
\hline Treatment of cervical cancer & $1,233,413$ & $1,013,599$ & $1,013,599$ \\
\hline Treatment of genital warts in females & $1,093,366$ & $1,093,360$ & 337,162 \\
\hline Treatment of genital warts in males & 556,932 & 556,924 & 178,880 \\
\hline Total direct costs & $15,429,116$ & $18,232,756$ & $17,039,658$ \\
\hline \multicolumn{4}{|l|}{ Indirect costs (due to work loss) } \\
\hline Treatment of CIN & $1,978,965$ & $1,618,578$ & $1,566,941$ \\
\hline Treatment of CIS & 338,862 & 234,758 & 234,758 \\
\hline Treatment of cervical cancer & 198,247 & 154,987 & 154,987 \\
\hline Treatment of genital warts in females & 58,878 & 58,878 & 18,156 \\
\hline Treatment of genital warts in males & 39,507 & 39,507 & 12,689 \\
\hline Total indirect costs & $2,614,460$ & $2,106,708$ & $1,987,532$ \\
\hline \multicolumn{4}{|l|}{ Total costs } \\
\hline Total direct and indirect costs & $18,043,576$ & $20,339,463$ & $19,027,190$ \\
\hline
\end{tabular}

CIN cervical intraepithelial neoplasia, CIS carcinoma in situ

Table 7 Base case cost-effectiveness results (3-dose schedule)

\begin{tabular}{|c|c|c|c|}
\hline Discounted costs $(€)$, health outcomes and ICERs & No vaccination & Bivalent vaccination & Quadrivalent vaccination \\
\hline Direct costs & $15,429,115,908$ & $18,232,755,877$ & $17,039,657,688$ \\
\hline Incremental direct costs ${ }^{\mathrm{a}}$ & - & $2,803,639,969$ & $1,610,541,780$ \\
\hline Direct and indirect costs & $18,043,576,056$ & $20,339,463,474$ & $19,027,189,752$ \\
\hline Incremental total costs ${ }^{\mathrm{a}}$ & - & $2,295,887,418$ & $983,613,696$ \\
\hline LYs lost & 377,884 & 325,779 & 325,779 \\
\hline Incremental LYs gained ${ }^{a}$ & - & 52,105 & 52,105 \\
\hline QALYs lost & 547,617 & 465,757 & 438,136 \\
\hline Incremental QALYs gained ${ }^{\mathrm{a}}$ & - & 81,860 & 109,481 \\
\hline ICER $(€ / L Y)$, health care payer perspective & - & 53,807 & 30,910 \\
\hline ICER $(€ / L Y)$, societal perspective & - & 44,063 & 18,878 \\
\hline ICER (€/QALY), health care payer perspective & - & 34,249 & 14,711 \\
\hline ICER (€/QALY), societal perspective & - & 28,047 & 8984 \\
\hline
\end{tabular}

ICER incremental cost-effectiveness ratio, $Q A L Y$ quality-adjusted life year, $L Y$ life year

a Compared to no vaccination

cases of cervical cancer (20\% coverage: 47,000 prevented cases; $10 \%$ coverage: 24,000 prevented cases). Consideration of vaccine-specific cross-protection benefits yielded ICERs of $€ 24,576$ per QALY (at an estimated reduction in cervical cancer cases of 119,000) for the bivalent vaccine and $€ 11,429$ per QALY (at approximately 113,000 prevented cervical cancer cases) for the quadrivalent vaccine when taking a health care payer perspective. Figure 2 shows the results of several one-way sensitivity analyses using the example of the quadrivalent vaccine with a 3-dose schedule.

In the best case scenario of the 3-dose schedule (6/11/16/18 efficacy: 100\%; vaccine-specific crossprotection: 32.5 or $68.4 \%$; lifelong protection; $20 \%$ 


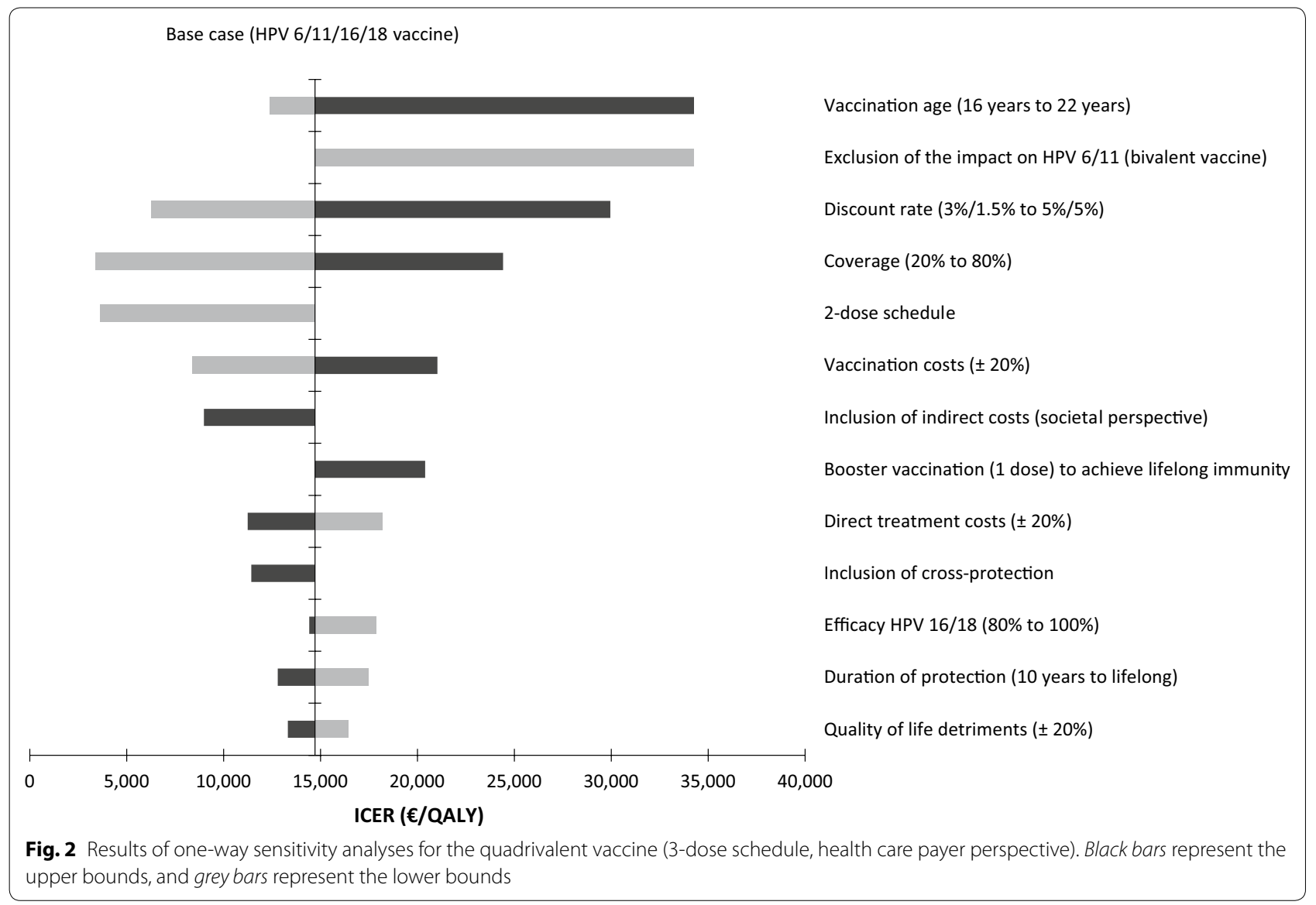

increase in screening and treatment cost; $20 \%$ increase in quality of life detriments; societal perspective), about 130,000 cervical cancer cases were prevented, and ICERs decreased to $€ 11,156$ per QALY for the bivalent vaccine and $€ 154$ per QALY for the quadrivalent vaccine. In the worst case scenario of the 3-dose schedule (6/11/16/18 efficacy: $80 \%$; no cross-protection; average duration of protection: 15 years; $20 \%$ decrease in screening and treatment cost; $20 \%$ decrease in quality of life detriments; health care payer perspective), about 80,000 cervical cancer cases were prevented and ICERs increased to $€ 50,300$ per QALY for the bivalent vaccine and $€ 26,532$ per QALY for the quadrivalent vaccine.

If the introduction of HPV vaccination was accompanied by an increase of the screening interval for all age cohorts (regardless of whether they received vaccination or not), cost offsets came along with net QALY losses (i.e. ICERs were located in the south-west quadrant of the cost-effectiveness plane) when compared to the existing screening practice and no vaccination.

A 2-dose schedule led to ICERs of $€ 19,450$ per QALY for the bivalent vaccine and $€ 3645$ per QALY for the quadrivalent vaccine when taking a health care payer perspective. When adopting a societal perspective, the use of the quadrivalent vaccine with a 2-dose approach appeared to be a cost-saving strategy and the ICER of a 2-dose schedule using the bivalent vaccine decreased to $€ 13,248$ per QALY.

Using base case assumptions for vaccinating girls (3-dose schedule with $50 \%$ coverage), additional vaccination of 12-year-old boys with three doses and a coverage of $50 \%$ resulted in ICERs of $€ 130,449$ per QALY for the bivalent vaccine and $€ 117,240$ per QALY for the quadrivalent vaccine from a health care payer perspective when compared with vaccinating girls alone. Assuming a low coverage in girls $(20 \%)$, the cost per QALY of vaccinating boys at a similar coverage level (20\%) decreased to $€ 57,024$ for the bivalent vaccine and to $€ 37,985$ for the quadrivalent vaccine. Assuming a high coverage in girls (80\%), additional vaccination of boys (regardless of the coverage level) resulted in ICERs of more than $€ 400,000$ per QALY for both vaccines. When using a 2-dose schedule and assuming that two doses are as effective as three doses, ICERs of vaccinating boys remained above $€ 50,000$ and $€ 200,000$ per QALY in scenarios with moderate and high coverage in girls, respectively. Results of additional vaccination of boys with two or three doses are summarised in Table 8. 


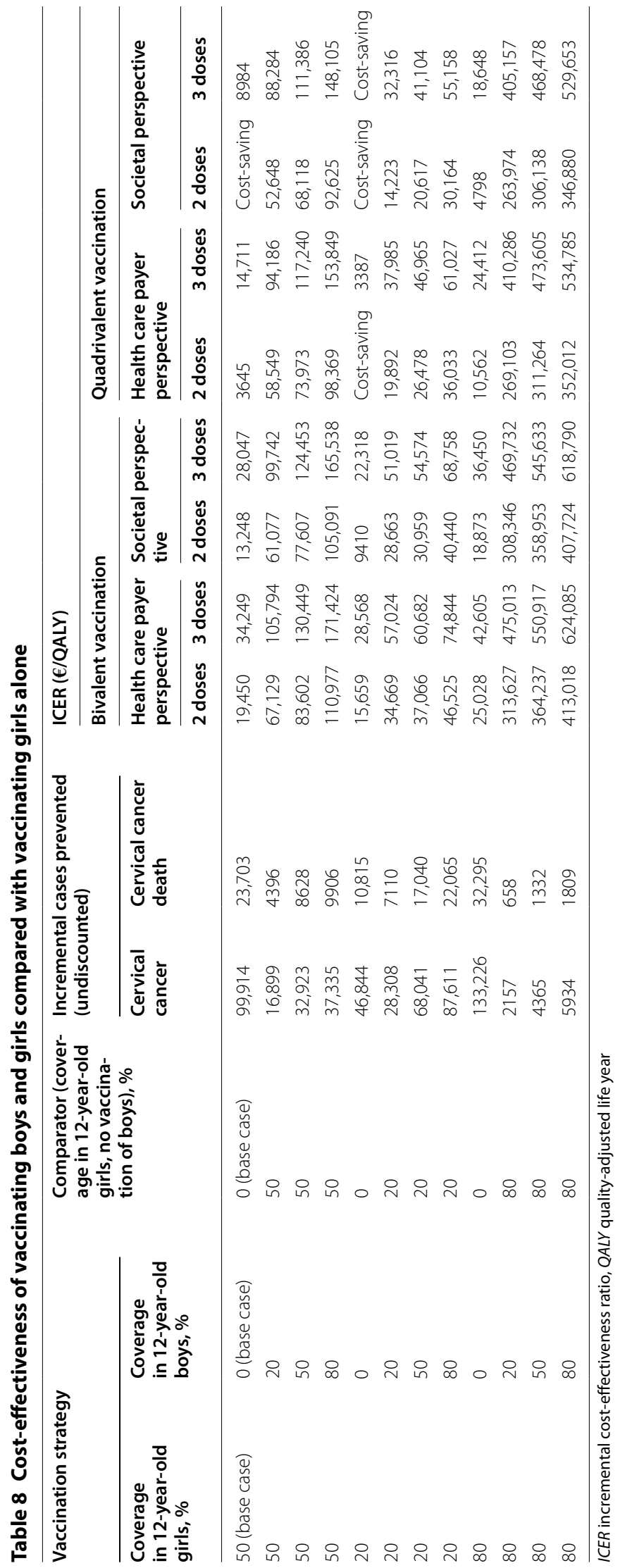




\section{Systematic literature review of previously published} economic evaluations of HPV vaccination in Germany The PubMed search resulted in 17 articles published before June 2016, of which three met the inclusion criteria [66-68]. One further study reflecting the German health care setting was identified by hand-searching reference lists [69]. Table 9 gives an overview of the included studies.

Hillemanns et al. [69] used a static cohort model to estimate the cost-effectiveness of vaccinating 12-yearold girls alongside the existing cervical cancer screening programme compared to screening alone from the German health care payer perspective. They performed a cost-effectiveness analysis (CEA) and a cost-utility analysis (CUA) of the quadrivalent vaccine assuming a lifelong duration of protection. ICERs of the base case analysis, in which effects on CIN, cervical cancer, and genital warts in women were considered, were $€ 15,684$ per LY and $€ 10,530$ per QALY. ICERs increased to $€ 16,689$ per LY and $€ 11,658$ per QALY when genital warts were excluded. Restricting the duration of vaccine-induced protection to 20 years almost doubled the ICERs (€28,991 per LY; $€ 19,445$ per QALY).

Schobert et al. [67] presented results of both a CEA and a CUA using a dynamic transmission model that has already been used to evaluate the cost-effectiveness of HPV vaccination in other countries. They estimated the economic impact of vaccinating girls aged 12-17 years with three doses of the quadrivalent vaccine from a health care payer perspective considering $\mathrm{HPV}$-associated diseases in women (CIN, cervical cancer and genitals warts) and men (genital warts). In the base case analysis, it was assumed that the vaccine provided lifelong protection, and the corresponding ICERs were $€ 10,205$ per LY and $€ 5525$ per QALY. The cost per QALY increased to about $€ 10,000$ when limiting the duration of protection to 20 years or excluding the protection of HPV6/11-associated diseases.

Kotsopoulos et al. [66] adopted a societal perspective and used a cost-benefit analysis (CBA) based on a static cohort model to quantify the economic impact of a 2-dose schedule of the quadrivalent vaccine in the prevention of HPV-related diseases in females and males (CIN, cervical, vaginal, vulvar and anal cancer, and genital warts). Female vaccination at the age of 12 years led to a benefit-cost ratio (BCR) of 3.3 meaning that $€ 1$ invested in HPV vaccination returns $€ 3.3$ in terms of prevented medical costs and productivity losses due to premature mortality. BCRs of male vaccination and universal vaccination (i.e. vaccination of males and females) were 0.3 and 1.8 , respectively. However, the CBA was limited to a cost comparison (including cost-offsets) as health benefits were not valued in monetary units. Therefore, from a methodological perspective and in accordance with the commonly accepted definition of CBA [70], this study offers only a partial evaluation.

Soergel et al. [68] developed a static model based on the conisation-related neonatal morbidity and mortality in Germany. They conducted both a CEA and a CUA of HPV 16/18 vaccination with measuring the effects of $\mathrm{HPV}$ vaccination in terms of a reduced number of conisations and a corresponding decrease in conisation-associated neonatal morbidity and mortality. When vaccinating 12 -year-old girls the cost per LY was $€ 45,101$ and the cost per QALY ranged from $€ 43,505$ to $€ 47,885$.

\section{Discussion}

\section{Summary of key findings}

In our model, vaccination of 12-year-old girls against HPV was associated with ICERs often considered as good value for money (below $€ 50,000$ per QALY). Additional protection against genital warts in females and males by the quadrivalent vaccine improved results substantially. This high impact of the HPV 6/11 component of the quadrivalent vaccine is largely due to the different time points at which prevention of HPV-associated outcomes occurs. Genital warts can be prevented relatively soon after vaccination, while the development of cervical cancer usually takes many years. Consequently, the discounting of future events leads to an emphasis on the prevention of genital warts and lowers the influence of avoided cervical cancer cases on the cost-effectiveness of HPV vaccination. In addition, the indirect benefits of preventing genital warts in males intensify the impact of the protection against HPV 6/11. However, when taking vaccine-specific cross-protection into account, estimated reduction in cervical cancer was higher for the bivalent vaccine than for the quadrivalent vaccine, despite a higher overall cost per QALY estimate. Inclusion of indirect costs lowered (improved) the ICERs by up to $40 \%$. An even bigger improvement of the cost-effectiveness was shown by using a 2-dose schedule instead of a 3-dose schedule when assuming that two doses are as protective as three doses. This substantial improvement was triggered by the reduction in vaccination costs. By contrast, additional vaccination of boys resulted in mainly high or very high cost-effectiveness ratios, except for scenarios with low coverage in girls. This finding is in line with previous research on the cost-effectiveness of including males in HPV vaccination programmes in high-income countries [71]. However, male HPV-related cancers were not considered in our analyses, and the model was restricted to heterosexual transmission of HPV infection. Studies focussing on men who have sex with men (MSM) showed that HPV vaccination of MSM is likely to be a cost-effective intervention [72-74]. 


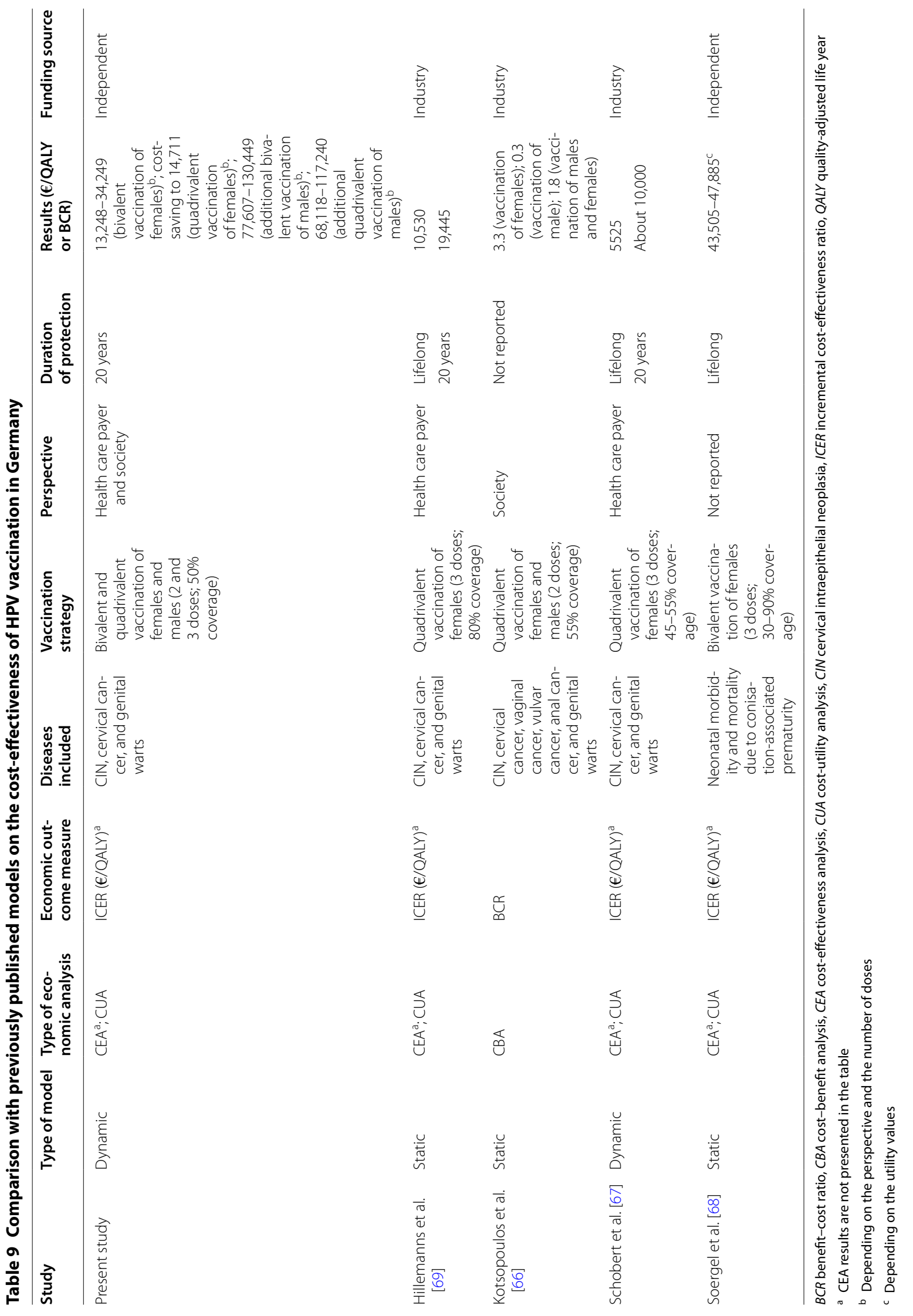




\section{Comparison with other models}

In other models reflecting the German health care setting, the cost per QALY of quadrivalent HPV vaccination with three doses ranged between $€ 10,000$ and $€ 20,000$ from a health care payer perspective when assuming a 20 years lasting duration of protection and considering effects on CIN, cervical cancer, and genital warts [67, 69]. Our estimate of $€ 14,711$ per QALY falls within this range of estimates. When adopting a societal perspective, quadrivalent HPV vaccination of 12-year-old girls with two doses resulted in cost savings in our model. This also compares well with previous findings [66]. In contrast, the study by Soergel et al. [68] allows no direct comparison with our estimates because it focussed on conisationassociated neonatal morbidity and mortality. However, Soergel et al. [68] showed that vaccinating girls against HPV 16/18 might even be cost-effective without considering the impact on cervical cancer.

\section{Strengths and limitations}

An important strength of our study is that we presented results for a wide range of scenarios varying the target group (female vaccination vs. no vaccination; female and male vaccination vs. female vaccination), coverage rate, and number of vaccine doses. Another strength is that we used a dynamic transmission model to estimate the costeffectiveness of HPV vaccination in Germany. Compared to static models, which account only for direct effects of vaccination, dynamic models also capture indirect effects in terms of herd protection [75]. Furthermore, we included the impact of historical changes in participation rates of the cytological cervical cancer screening in Germany. This is one reason why our model might provide more accurate results than the dynamic model from Schobert et al. [67]. In addition, we applied a more comprehensive calibration approach than the aforementioned model and used agespecific epidemiological data for several calibration targets.

We acknowledge that our model also has several limitations. First, we did not include other cancers than cervical cancer. Other modelling studies showed that considering the impact on vaginal, vulvar, penile, anal, and head and neck cancer could improve the cost-effectiveness of HPV vaccination [76, 77]. However, our model reflects the goal of the current German HPV immunisation recommendation, which is defined (by STIKO) as the reduction in disease burden caused by cervical cancer. Second, our model evaluated the cost-effectiveness of the bivalent and quadrivalent vaccines, but did not include the new 9-valent HPV vaccine, which was introduced in Germany after completion of this study. However, we investigated the impact of including vaccine-specific cross-protection against non-vaccine high-risk HPV types in sensitivity analyses, and corresponding results might give an impression of the cost-effectiveness of higher-valent vaccines. We recommend including the 9-valent HPV vaccine in future modelling studies. Third, our model did not account for potential cross-protection of the bivalent vaccine against low-risk HPV types. Results of an ecological study suggest that there might be a moderate cross-protective effect of the bivalent vaccine against genital warts since the rates of genital warts have declined after the introduction of a national HPV vaccination programme using the bivalent vaccine in England [78]. In addition, a post hoc analysis of a clinical trial showed that the bivalent vaccine provides a moderate efficacy against persistent infection with low-risk HPV types [79]. Nevertheless, the underlying biological mechanisms of these findings have not yet been clarified conclusively. Fourth, in our base case analysis, we assumed a vaccination age of 12 years in order to ensure comparability with other studies although most girls in Germany have received the first dose in the age of 13 or 14 years [28]. However, the updated immunisation recommendation favours a younger vaccination age (from 9 years), which might impact future health and economic effects of HPV vaccination. Fifth, modelling of cervical cancer screening was based on cytological screening, which predominantly reflects the current screening practice in Germany. However, future changes to cervical cancer screening may involve primary HPV testing [80]. Sixth, input data on sexual behaviour were based on surveys from other European countries, and actual behaviour in Germany might differ from that in other countries. Seventh, due to the lack of German-specific utility values, the utility estimates we used in our model were taken from international studies with some of them resting on expert opinion. Furthermore, we assumed a baseline utility value of 1.0 in the absence of HPV-associated diseases, which might lead to a potential overestimation of HPV-related QALY losses. However, sensitivity analyses showed that variations in utilities had limited impact on the results. Eighth, since we used a stable population approach, our model did not take account of demographic trends and their implications.

\section{Conclusions}

Considering the often-cited threshold of $€ 50,000$ per QALY, our model results suggest that routine HPV vaccination of 12-year-old girls with three doses is likely to be cost-effective in Germany. Due to the additional impact on HPV 6/11-related diseases (mostly genital warts), the quadrivalent vaccine appeared to be more cost-effective than the bivalent vaccine, even when considering the higher cross-protection of the bivalent vaccine. Most of these findings are consistent with results predicted by previously published industry-funded models of HPV vaccination in Germany. Our model also showed that a 
2-dose schedule of the quadrivalent vaccine could result in cost savings when assuming an equivalent level of protection and adopting a societal perspective. Additional vaccination of boys was found to be a cost-effective strategy in scenarios with low coverage in girls. However, there is a need for an extended version of this model that also accounts for the potential impact on non-cervical cancer types in both genders since the consideration of this aspect might lead to more favourable results regarding the additional vaccination of boys in scenarios with moderate or high coverage in girls.

\begin{abstract}
Abbreviations
BCR: benefit-cost ratio; CBA: cost-benefit analysis; CEA: cost-effectiveness analysis; CIN: cervical intraepithelial neoplasia; CIS: carcinoma in situ; CPI: consumer price index; CUA: cost-utility analysis; DRG: diagnosis-related group; EBM: Einheitlicher Bewertungsmaßstab; FIGO: International Federation of Gynecology and Obstetrics; HPV: human papillomavirus; HUI: Health Utility Index; ICER: incremental cost-effectiveness ratio; QALY: quality-adjusted life year; MSM: men who have sex with men; RKI: Robert Koch Institute; SIRS: susceptible-infectious-recovered-susceptible; STIKO: Ständige Impfkommission (Standing Vaccination Committee).
\end{abstract}

\section{Authors' contributions}

$\mathrm{OD}$ and $\mathrm{JH}$ designed the study, developed the model, performed the data collection, carried out the analyses, and interpreted the results. OD conducted the interviews with clinical experts, performed the cost calculations, and drafted the manuscript. JH programmed and calibrated the model. AMK and YD helped to select the model input values and provided clinical expert advice. MEEK contributed to the study design and provided methodological expert advice. RTM and WG contributed to the study design, participated in the interpretation of the results, and supervised the project. All authors critically reviewed the initial draft. All authors read and approved the final manuscript.

\section{Author details \\ ${ }^{1}$ Department of Health Economics and Health Care Management, School of Public Health, Bielefeld University, Universitätsstraße 25, 33615 Bielefeld, Germany. ${ }^{2}$ Epidemiological and Statistical Methods Research Group, Helm- holtz Centre for Infection Research, Braunschweig, Germany. ${ }^{3}$ Hannover Medi- cal School, Hannover, Germany. ${ }^{4}$ German Centre for Infection Research, Site Hannover-Braunschweig, Hannover/Braunschweig, Germany. ${ }^{5}$ Julius Center for Health Sciences and Primary Care, University Medical Center Utrecht, Utre- cht, The Netherlands. ${ }^{6}$ Centre for Infectious Disease Control, RIVM, Bilthoven, The Netherlands. ${ }^{7}$ Gynecologic Tumor Immunology, Clinic for Gynecology, Charité-Universitätsmedizin Berlin, Berlin, Germany. ${ }^{8}$ Praxis Löser/Kaden/ Deleré/Knappe, Berlin, Germany. ${ }^{9}$ Immunisation Unit, Robert Koch Institute, Berlin, Germany. ${ }^{10}$ Department of Public Health Medicine, School of Public Health, Bielefeld University, Bielefeld, Germany.}

\section{Acknowledgements}

We thank Matthias W. Beckmann (University Hospital Erlangen, Erlangen, Germany), Christian Dannecker (Hospital of the Ludwig-Maximilians-University München, München, Germany), Ingke Hagemann (abts + partner, Kiel, Germany), Peter Hillemanns (Hannover Medical School, Hannover, Germany), Karl U. Petry (Wolfsburg Clinic, Wolfsburg, Germany), Achim Schneider (CharitéUniversitätsmedizin Berlin, Berlin, Germany) and the members of the German working group on cervical pathology and colposcopy for participating in the expert interviews. We also thank Julian Witte (Bielefeld University, Bielefeld, Germany) for his assistance in collecting unit cost data. We acknowledge support for the Article Processing Charge by the Deutsche Forschungsgemeinschaft and the Open Access Publication Fund of Bielefeld University.

\section{Competing interests}

OD and WG have conducted studies for Sanofi Pasteur MSD and GlaxoSmithKline unrelated to the current study. All other authors have no competing interests to declare.
Availability of data and materials

Not applicable.

\section{Consent for publication}

Not applicable.

\section{Ethics approval and consent to participate}

Not applicable.

\section{Funding}

The study was fully funded by Robert Koch Institute (Project Number: 1362/1-927).

\section{Publisher's Note}

Springer Nature remains neutral with regard to jurisdictional claims in published maps and institutional affiliations.

Received: 8 September 2016 Accepted: 23 August 2017

Published online: 04 September 2017

References

1. Bosch FX, Lorincz A, Muñoz N, Meijer CJLM, Shah KV. The causal relation between human papillomavirus and cervical cancer. J Clin Pathol. 2002;55:244-65.

2. Gillison ML, Chaturvedi AK, Lowy DR. HPV prophylactic vaccines and the potential prevention of noncervical cancers in both men and women. Cancer. 2008;113:3036-46.

3. Grulich AE, Jin F, Conway EL, Stein AN, Hocking J. Cancers attributable to human papillomavirus infection. Sex Health. 2010;7:244-52.

4. Dunne EF, Markowitz LE. Genital human papillomavirus infection. Clin Infect Dis. 2006:43:624-9.

5. Deleré Y, Wichmann O, Klug SJ, van der Sande M, Terhardt M, Zepp F, Harder T. The efficacy and duration of vaccine protection against human papillomavirus: a systematic review and meta-analysis. Dtsch Arztebl Int. 2014;111:584-91.

6. Kash N, Lee MA, Kollipara R, Downing C, Guidry J, Tyring SK. Safety and efficacy data on vaccines and immunization to human papillomavirus. J Clin Med. 2015;4:614-33.

7. Lu B, Kumar A, Castellsagué X, Giuliano AR. Efficacy and safety of prophylactic vaccines against cervical HPV infection and diseases among women: a systematic review \& meta-analysis. BMC Infect Dis. 2011;11:13.

8. Muñoz N, Bosch FX, Castellsagué X, Díaz M, de Sanjose S, Hammouda D, Shah KV, Meijer CJ. Against which human papillomavirus types shall we vaccinate and screen? The international perspective. Int J Cancer. 2004;111:278-85.

9. Greer CE, Wheeler CM, Ladner MB, Beutner K, Coyne MY, Liang H, Langenberg A, Yen TS, Ralston R. Human papillomavirus (HPV) type distribution and serological response to HPV type 6 virus-like particles in patients with genital warts. J Clin Microbiol. 1995;33:2058-63.

10. Ständige Impfkommission. Empfehlungen der Ständigen Impfkommission (STIKO) am Robert Koch-Institut/Stand: August 2014. Epidemiol Bull. 2014;34(2014):305-40.

11. Ständige Impfkommission. Wissenschaftliche Begründung für die Änderung der Empfehlung zur Impfung gegen humane Papillomviren. Epidemiol Bull. 2014;35(2014):343-7.

12. Horn J, Damm O, Kretzschmar MEE, Deleré Y, Wichmann O, Kaufmann AM, Garbe E, Krämer A, Greiner W, Mikolajczyk RT. Estimating the long-term effects of HPV vaccination in Germany. Vaccine. 2013;31:2372-80.

13. Choi YH, Jit M, Gay N, Cox A, Garnett GP, Edmunds WJ. Transmission dynamic modelling of the impact of human papillomavirus vaccination in the United Kingdom. Vaccine. 2010;28:4091-102.

14. Elbasha EH, Dasbach EJ, Insinga RP. Model for assessing human papillomavirus vaccination strategies. Emerg Infect Dis. 2007;13:28-41.

15. Zechmeister I, de Blasio BF, Garnett G, Neilson AR, Siebert U. Costeffectiveness analysis of human papillomavirus-vaccination programs to prevent cervical cancer in Austria. Vaccine. 2009;27:5133-41. 
16. Canfell K, Barnabas R, Patnick J, Beral V. The predicted effect of changes in cervical screening practice in the UK: results from a modelling study. $\mathrm{Br} J$ Cancer. 2004;91:530-6.

17. Elbasha EH, Dasbach EJ, Insinga RP. A multi-type HPV transmission model. Bull Math Biol. 2008;70:2126-76.

18. Kohli M, Ferko N, Martin A, Franco EL, Jenkins D, Gallivan S, Sherlaw-Johnson C, Drummond M. Estimating the long-term impact of a prophylactic human papillomavirus 16/18 vaccine on the burden of cervical cancer in the UK. Br J Cancer. 2007;96:143-50.

19. Schneider A, Hammerschmidt T, Schwarz TF, Rogoza RM, Ferko N, Siebert U. Long-term public health impact of vaccination against cervical cancer in Germany. Geburtshilfe Frauenheilkd. 2007;67:850-8.

20. Sroczynski G, Schnell-Inderst P, Mühlberger N, Lang K, Aidelsburger $P$, Wasem J, MittendorfT, Engel J, Hillemanns P, Petry K, Krämer A, Siebert U. Entscheidungsanalytische Modellierung zur Evaluation der LangzeitEffektivität und Kosten-Effektivität des Einsatzes der HPV-DNA-Diagnostik im Rahmen der Zervixkarzinomfrüherkennung in Deutschland. Köln: Deutsches Institut für Medizinische Dokumentation und Information; 2010

21. Mikolajczyk RT, Horn J, Damm O, Kaufmann AM, Kretzschmar MEE. Epidemiological study of anti-HPV-16/18 seropositivity and subsequent risk of HPV-16 and -18 infections. J Natl Cancer Inst. 2012;104:163.

22. Carter JJ, Koutsky LA, Hughes JP, Lee SK, Kuypers J, Kiviat N, Galloway DA. Comparison of human papillomavirus types 16,18 , and 6 capsid antibody responses following incident infection. J Infect Dis. 2000;181:1911-9.

23. Safaeian M, Porras C, Schiffman M, Rodriguez AC, Wacholder S, Gonzalez P, Quint W, van Doorn L, Sherman ME, Xhenseval V, Herrero R, Hildesheim A. Epidemiological study of anti-HPV16/18 seropositivity and subsequent risk of HPV16 and -18 infections. J Natl Cancer Inst. 2010;102:1653-62.

24. Insinga RP, Dasbach EJ, Elbasha EH. Epidemiologic natural history and clinical management of human papillomavirus (HPV) disease: a critical and systematic review of the literature in the development of an HPV dynamic transmission model. BMC Infect Dis. 2009;9:119.

25. Kerek-Bodden H, Altenhofen L, Brenner G. Durchführung einer versichertenbezogenen Untersuchung zur Inanspruchnahme der Früherkennung auf Zervixkarzinom in den Jahren 2002, 2003 und 2004 auf der Basis von Abrechnungsdaten. Berlin: Zentralinstitut für die kassenärztliche Versorgung in der Bundesrepublik Deutschland; 2009.

26. Robert Koch-Institut. Gesundheit in Deutschland. Berlin: Robert KochInstitut; 2006.

27. Deleré Y, Böhmer MM, Walter $D$, Wichmann O. HPV vaccination coverage among women aged 18-20 years in Germany three years after recommendation of HPV vaccination for adolescent girls: results from a crosssectional survey. Hum Vaccines Immunother. 2013;9:1706-11.

28. Poethko-Müller C, Buttmann-Schwelger N, KiGGS Study Group. Impfstatus und Determinanten der Impfung gegen humane Papillomviren (HPV) bei Mädchen in Deutschland. Bundesgesundheitsblatt Gesundheitsforschung Gesundheitsschutz. 2014;57:869-77.

29. Remschmidt C, Fesenfeld M, Kaufmann AM, Deleré Y. Sexual behavior and factors associated with young age at first intercourse and HPV vaccine uptake among young women in Germany: implications for HPV vaccination policies. BMC Public Health. 2014:14:1248.

30. RieckT, Feig M, Deleré Y, Wichmann O. Utilization of administrative data to assess the association of an adolescent health check-up with human papillomavirus vaccine uptake in Germany. Vaccine. 2014;32:5564-9.

31. Roggendorf H. Erste Erfahrungen zur Akzeptanz der HPV-Impfung. Monatsschr Kinderheilkd. 2009;157:982-5.

32. Stöcker $P$, Dehnert $M$, Schuster M, Wichmann O, Deleré Y. Human papillomavirus vaccine uptake, knowledge and attitude among 10th grade students in Berlin, Germany, 2010. Hum Vaccines Immunother. 2013;9:74-82.

33. de Vincenzo R, Conte C, Ricci C, Scambia G, Capelli G. Long-term efficacy and safety of human papillomavirus vaccination. Int J Womens Health. 2014;6:999-1010.

34. David M, van Herck K, Hardt K, Tibaldi F, Dubin G, Descamps D, van Damme P. Long-term persistence of anti-HPV-16 and -18 antibodies induced by vaccination with the AS04-adjuvanted cervical cancer vaccine: modeling of sustained antibody responses. Gynecol Oncol. 2009;115:S1-6.

35. Fraser C, Tomassini JE, Xi L, Golm G, Watson M, Giuliano AR, Barr E, Ault KA. Modeling the long-term antibody response of a human papillomavirus (HPV) virus-like particle (VLP) type 16 prophylactic vaccine. Vaccine. 2007:25:4324-33.
36. Beckmann MW, Mehlkorn G, Thiel F, Breuel C, Fasching PA, Ackermann S. Therapiefortschritte beim primären Zervixkarzinom. Dtsch Arztebl. 2005;102:A979-86

37. Dannecker $C$, Hantschmann P, Friese K. Stadienbezogene Therapie des Zervixkarzinoms. Gynäkologe. 2008:41:349.

38. Deutsche Krebsgesellschaft, Deutsche Gesellschaft für Gynäkologie und Geburtshilfe, Arbeitsgemeinschaft Gynäkologische Onkologie. Diagnostik und Therapie des Zervixkarzinoms, AWMF 032/033 (S2k). Berlin: Deutsche Gesellschaft für Gynäkologie und Geburtshilfe; 2008.

39. Hillemanns P. Manual Zervixkarzinom. 3rd ed. München: Tumorzentrum München und W. Zuckschwerdt Verlag GmbH; 2004.

40. LAUER-TAXE. LAUER-FISCHER GmbH. http://www2.lauer-fischer.de. Accessed 17 Sept 2012.

41. Petry KU, Breugelmans JG, Bénard S, Lamure E, Littlewood KJ, Hillemanns P. Cost of screening and treatment of cervical dyskaryosis in Germany. Eur J Gynaecol Oncol. 2008:29:345-9.

42. Hillemanns P, Breugelmans JG, Gieseking F, Bénard S, Lamure E, Littlewood $\mathrm{KJ}$, Petry KU. Estimation of the incidence of genital warts and the cost of illness in Germany: a cross-sectional study. BMC Infect Dis. 2008;8:76.

43. Krankheitsartenstatistik (Versicherte der Allgemeinen Ortskrankenkassen). AOK-Bundesverband. 2008. http://www.gbe-bund.de. Accessed 17 Sept 2012.

44. Bundesagentur für Arbeit. Arbeitsmarkt 2009. Nürnberg: Bundesagentur für Arbeit; 2010.

45. Statistisches Bundesamt. Deutsche Wirtschaft 2010. Wiesbaden: Statistisches Bundesamt; 2011.

46. Brisson M, Van de Velde N, de Wals P, Boily M. The potential cost-effectiveness of prophylactic human papillomavirus vaccines in Canada. Vaccine. 2007:25:5399-408.

47. Insinga RP, Glass AG, Myers ER, Rush BB. Abnormal outcomes following cervical cancer screening: event duration and health utility loss. Med Decis Making. 2007;27:414-22.

48. Institute of Medicine (U.S.). Commitee to Study Priorities for Vaccine Development. Vaccines for the 21st century: a tool for decisionmaking. Washington, D.C.: National Academy Press; 2000.

49. Institut für Qualität und Wirtschaftlichkeit im Gesundheitswesen. Allgemeine Methoden, Version 4.2. KöIn: Institut für Qualität und Wirtschaftlichkeit im Gesundheitswesen; 2015

50. von der Schulenburg JMG, Greiner W, Jost F, Klusen N, Kubin M, Leidl R, MittendorfT, Rebscher H, Schoeffski O, Vauth C, Volmer T, Wahler S, Wasem J, Weber C. German recommendations on health economic evaluation: third and updated version of the Hanover consensus. Value Health. 2008;11:539-44.

51. Damm O, Ultsch B. Health economic evaluation of vaccines. Gesundh ökon Qual Manag. 2015:20:163-72.

52. Dobson SRM, McNeil S, Dionne M, Dawar M, Ogilvie G, Krajden M, Sauvageau C, Scheifele DW, Kollmann TR, Halperin SA, Langley JM, Bettinger JA, Singer J, Money D, Miller D, Naus M, Marra F, Young E. Immunogenicity of 2 doses of HPV vaccine in younger adolescents vs 3 doses in young women: a randomized clinical trial. JAMA. 2013;309:1793-802.

53. Kreimer AR, Struyf F, Rosario-Raymundo Del, Rowena Maria, Hildesheim A, Skinner SR, Wacholder S, Garland SM, Herrero R, David M, Wheeler CM, González P, Jiménez S, Lowy DR, Pinto LA, Porras C, Rodriguez AC, Safaeian M, Schiffman M, Schiller JT, Schussler J, Sherman ME, Bosch FX, Castellsague X, Chatterjee A, Chow S, Descamps D, Diaz-Mitoma F, Dubin G, Germar MJ, Harper DM, et al. Efficacy of fewer than three doses of an HPV-16/18 AS04-adjuvanted vaccine: combined analysis of data from the Costa Rica vaccine and PATRICIA trials. Lancet Oncol. 2015;16:775-86.

54. Romanowski B, Schwarz TF, Ferguson LM, Ferguson M, Peters K, Dionne M, Schulze K, Ramjattan B, Hillemanns P, Behre U, Suryakiran P, Thomas F, Struyf F. Immune response to the HPV-16/18 AS04-adjuvanted vaccine administered as a 2-dose or 3-dose schedule up to 4 years after vaccination: results from a randomized study. Hum Vaccines Immunother. 2014;10:1155-65.

55. Forhan SE, Gottlieb SL, Sternberg MR, Xu F, Datta SD, McQuillan GM, Berman SM, Markowitz LE. Prevalence of sexually transmitted infections among female adolescents aged 14 to 19 in the United States. Pediatrics. 2009:124:1505-12.

56. Iftner T, Eberle S, Iftner A, Holz B, Banik N, Quint W, Straube A. Prevalence of low-risk and high-risk types of human papillomavirus and other risk factors for HPV infection in Germany within different age groups in 
women up to 30 years of age: an epidemiological observational study. $\rfloor$ Med Virol. 2010;82:1928-39.

57. Klug SJ, Hukelmann M, Hollwitz B, Düzenli N, Schopp B, Petry K, Iftner T. Prevalence of human papillomavirus types in women screened by cytology in Germany. J Med Virol. 2007;79:616-25.

58. de Sanjosé S, Diaz M, Castellsagué X, Clifford G, Bruni L, Muñoz N, Bosch FX. Worldwide prevalence and genotype distribution of cervical human papillomavirus DNA in women with normal cytology: a meta-analysis. Lancet Infect Dis. 2007;7:453-9.

59. Schneider A, Hoyer H, Lotz B, Leistritza S, Kühne-Heid R, Nindl I, Müller B, Haerting J, Dürst M. Screening for high-grade cervical intra-epithelial neoplasia and cancer by testing for high-risk HPV, routine cytology or colposcopy. Int J Cancer. 2000;89:529-34.

60. Peto J, Gilham C, Deacon J, Taylor C, Evans C, Binns W, Haywood M, Elanko $\mathrm{N}$, Coleman D, Yule R, Desai M. Cervical HPV infection and neoplasia in a large population-based prospective study: the Manchester cohort. Br J Cancer. 2004;91:942-53.

61. GEKID-Atlas. Gesellschaft der epidemiologischen Krebsregister in Deutschland. http://www.gekid.de. Accessed 17 Sept 2012.

62. Castellsagué X, de Sanjose S, Aguado T, Louie KS, Bruni L, Muñoz N, Diaz M, Irwin K, Gacic M, Beauvais O, Albero G, Ferrer E, Byrne S, Bosch FX. HPV and cervical cancer in the 2007 report. Vaccine. 2007;25(Suppl 3):C1-230.

63. Clifford GM, Gallus S, Herrero R, Muñoz N, Snijders PJF, Vaccarella S, Anh PTH, Ferreccio C, Hieu NT, Matos E, Molano M, Rajkumar R, Ronco G, de Sanjosé S, Shin HR, Sukvirach S, Thomas JO, Tunsakul S, Meijer CJLM, Franceschi S. Worldwide distribution of human papillomavirus types in cytologically normal women in the International Agency for Research on Cancer HPV prevalence surveys: a pooled analysis. Lancet. 2005;366:991-8.

64. Clifford GM, Rana RK, Franceschi S, Smith JS, Gough G, Pimenta JM. Human papillomavirus genotype distribution in low-grade cervical lesions: comparison by geographic region and with cervical cancer. Cancer Epidemiol Biomark Prev. 2005;14:1157-64.

65. Smith JS, Lindsay L, Hoots B, Keys J, Franceschi S, Winer R, Clifford GM. Human papillomavirus type distribution in invasive cervical cancer and high-grade cervical lesions: a meta-analysis update. Int J Cancer. 2007;121:621-32.

66. Kotsopoulos N, Connolly MP, Remy V. Quantifying the broader economic consequences of quadrivalent human papillomavirus (HPV) vaccination in Germany applying a government perspective framework. Health Econ Rev. 2015;5:54.

67. Schobert D, Remy V, Schoeffski O. Cost-effectiveness of vaccination with a quadrivalent HPV vaccine in Germany using a dynamic transmission model. Health Econ Rev. 2012;2:19.

68. Soergel P, Makowski L, Schippert C, Staboulidou I, Hille U, Hillemanns P. The cost efficiency of HPV vaccines is significantly underestimated due to omission of conisation-associated prematurity with neonatal mortality and morbidity. Hum Vaccines Immunother. 2012;8:243-51.

69. Hillemanns P, Petry KU, Largeron N, McAllister R, Tolley K, Büsch K. Costeffectiveness of a tetravalent human papillomavirus vaccine in Germany. J Public Health. 2009;17:77-86.

70. Zarnke KB, Levine MA, O'Brien BJ. Cost-benefit analyses in the healthcare literature: don't judge a study by its label. J Clin Epidemiol. 1997;50:813-22.

71. Yahia MBBH, Jouin-Bortolotti A, Dervaux B. Extending the human papillomavirus vaccination programme to include males in high-income countries: a systematic review of the cost-effectiveness studies. Clin Drug Investig. 2015:35:471-85.

72. Kim JJ. Targeted human papillomavirus vaccination of men who have sex with men in the USA: a cost-effectiveness modelling analysis. Lancet Infect Dis. 2010;10:845-52.

73. Deshmukh AA, Chiao EY, Das P, Cantor SB. Clinical effectiveness and costeffectiveness of quadrivalent human papillomavirus vaccination in HIVnegative men who have sex with men to prevent recurrent high-grade anal intraepithelial neoplasia. Vaccine. 2014;32:6941-7.

74. Lin A, Ong KJ, Hobbelen P, King E, Mesher D, Edmunds WJ, Sonnenberg P, Gilson R, Bains I, Choi YH, Tanton C, Soldan K, Jit M. Impact and costeffectiveness of selective human papillomavirus vaccination of men who have sex with men. Clin Infect Dis. 2017;64:580-8.
75. Ultsch B, Damm O, Beutels P, Bilcke J, Brüggenjürgen B, Gerber-Grote A, Greiner W, Hanquet G, Hutubessy R, Jit M, Knol M, von Kries R, Kuhlmann A, Levy-Bruhl D, Perleth M, Postma M, Salo H, Siebert U, Wasem J, Wichmann O. Methods for health economic evaluation of vaccines and immunization decision frameworks: a consensus framework from a European vaccine economics community. Pharmacoeconomics. 2016;34:227-44.

76. de Kok IMCM, Habbema JDF, van Rosmalen J, van Ballegooijen M. Would the effect of HPV vaccination on non-cervical HPV-positive cancers make the difference for its cost-effectiveness? Eur J Cancer. 2011;47:428-35.

77. Olsen J, Jørgensen TR. Revisiting the cost-effectiveness of universal HPVvaccination in Denmark accounting for all potentially vaccine preventable HPV-related diseases in males and females. Cost Eff Resour Alloc. 2015;13:4.

78. Canvin M, Sinka K, Hughes G, Mesher D. Decline in genital warts diagnoses among young women and young men since the introduction of the bivalent HPV (16/18) vaccination programme in England: an ecological analysis. Sex Transm Infect. 2016. doi:10.1136/sextrans-2016-052626.

79. Szarewski A, Skinner SR, Garland SM, Romanowski B, Schwarz TF, Apter D, Chow SN, Paavonen J, Del Rosario-Raymundo MR, Teixeira JC, De Carvalho NS, Castro-Sanchez M, Castellsagué X, Poppe WAJ, De Sutter P, Huh W, Chatterjee A, Tjalma WA, Ackerman RT, Martens M, Papp KA, BajoArenas J, Harper DM, Torné A, David MP, Struyf F, Lehtinen M, Dubin G. Efficacy of the HPV-16/18 AS04-adjuvanted vaccine against low-risk HPV types (PATRICIA randomized trial): an unexpected observation. J Infect Dis. 2013;208:1391-6.

80. Luyten A, Buttmann-Schweiger N, Luyten K, Mauritz C, Reinecke-Lüthge A, Pietralla M, Meijer CJLM, Petry KU. Early detection of CIN3 and cervical cancer during long-term follow-up using HPV/Pap smear co-testing and risk-adapted follow-up in a locally organised screening programme. Int J Cancer. 2014;135:1408-16.

81. Paavonen J, Naud P, Salmerón J, Wheeler CM, Chow S, Apter D, Kitchener H, Castellsague X, Teixeira JC, Skinner SR, Hedrick J, Jaisamrarn U, Limson G, Garland S, Szarewski A, Romanowski B, Aoki FY, Schwarz TF, Poppe WAJ, Bosch FX, Jenkins D, Hardt K, Zahaf T, Descamps D, Struyf F, Lehtinen M, Dubin G. Efficacy of human papillomavirus (HPV)-16/18 AS04-adjuvanted vaccine against cervical infection and precancer caused by oncogenic HPV types (PATRICIA): final analysis of a double-blind, randomised study in young women. Lancet. 2009;374:301-14.

82. The FUTURE II Study Group. Quadrivalent vaccine against human papillomavirus to prevent high-grade cervical lesions. N Engl J Med. 2007:356:1915-27.

83. Garland SM, Hernandez-Avila M, Wheeler CM, Perez G, Harper DM, Leodolter ST, Grace WK, Ferris DG, Steben M, Bryan J, Taddeo FJ, Railkar R, Esser MT, Sings HL, Nelson M, Boslego J, Sattler C, Barr E, Koutsky LA. Quadrivalent vaccine against human papillomavirus to prevent anogenital diseases. N Engl J Med. 2007;356:1928-43.

84. Giuliano AR, Palefsky JM, Goldstone S, Moreira ED, Penny ME, Aranda C, Vardas E, Moi H, Jessen H, Hillman R, Chang Y, Ferris D, Rouleau D, Bryan J, Marshall JB, Vuocolo S, Barr E, Radley D, Haupt RM, Guris D. Efficacy of quadrivalent HPV vaccine against HPV Infection and disease in males. N Engl J Med. 2011;364:401-11.

85. Brown DR, Kjaer SK, Sigurdsson K, Iversen O, Hernandez-Avila M, Wheeler CM, Perez G, Koutsky LA, Tay EH, Garcia P, Ault KA, Garland SM, Leodolter S, Olsson S, Tang GWK, Ferris DG, Paavonen J, Steben M, Bosch FX, Dillner J, Joura EA, Kurman RJ, Majewski S, Muñoz N, Myers ER, Villa LL, Taddeo FJ, Roberts C, Tadesse A, Bryan J, et al. The impact of quadrivalent human papillomavirus (HPV; types 6, 11, 16, and 18) L1 virus-like particle vaccine on infection and disease due to oncogenic nonvaccine HPV types in generally HPV-naive women aged 16-26 years. J Infect Dis. 2009;199:926-35.

86. Szarewski A. HPV vaccine: cervarix. Expert Opin Biol Ther. 2010;10:477-87.

87. Goldie SJ, Kohli M, Grima D, Weinstein MC, Wright TC, Bosch FX, Franco E. Projected clinical benefits and cost-effectiveness of a human papillomavirus 16/18 vaccine. J Natl Cancer Inst. 2004:96:604-15.

88. Gold MR, Franks P, McCoy KI, Fryback DG. Toward consistency in costutility analyses: using national measures to create condition-specific values. Med Care. 1998;36:778-92.

89. de Kok IMCM, van Ballegooijen M, Habbema JDF. Cost-effectiveness analysis of human papillomavirus vaccination in the Netherlands. J Natl Cancer Inst. 2009;101:1083-92. 